\title{
Well-Being Data Gathering during COVID-19: \\ Exploring the Feasibility of a Contact Tracing and Community Well-Being Safeguarding Framework
}

\author{
Laura Musikanski $^{1}$ (D) Rhonda Phillips $^{2} \cdot$ Paul Rogers $^{3}$
}

Received: 12 August 2020 / Accepted: 14 December 2020/Published online: 7 January 2021

(C) The Author(s), under exclusive licence to Springer Nature Switzerland AG part of Springer Nature 2021

\begin{abstract}
Given the need for real time data to aid in decision-making at the community level, contact tracing applications (apps) are explored as a potential method of gauging overall community well-being. The context of contact tracing effectiveness and integration with artificial intelligence is provided, as well as ideas and suggestions for how to expand for use as a community-wide data gathering approach. This commentary seeks to explore dimensions around the use of such apps to help manage in times of crisis given the widespread and destructive impacts the pandemic has on community well-being, including negative economic impacts and social declines. By connecting with community well-being, the idea of a contact tracing framework would enable communities to track data and make decisions to help foster well-being across public health, economic and social domains.
\end{abstract}

Keywords COVID-19 · Contract tracing · Community well-being $\cdot$ Resilience

Laura Musikanski

laura@happycounts.org

Rhonda Phillips

rphillips@purdue.edu

Paul Rogers

paul@happycounts.org

1 Happiness Alliance, Seattle, WA, USA

2 Purdue University Honors College, West Lafayette, IN, USA

3 Planet Happiness, Lennox Head, New South Wales, Australia 


\section{Introduction}

Contact tracing is the act of listing, contacting and following up with anyone who spent a certain amount of time (such as fifteen minutes or more) within a certain distance (such as less than six feet) of an infected person (World Health Organization 2017). The aim of contact tracing is to control the spread of a contagion, such as the severe acute respiratory syndrome (SARS)-CoV-2, more commonly known as COVID-19 (Centers for Disease Control and Prevention 2020). COVID-19 is the illness, and SARS-CoV-2 is the contagion but we use the term COVID-19 for both in this commentary.

Historically, contact tracing has entailed public officials or health care workers collecting information from an infected person about whom they have been in contact with and then reaching out to those people (Chen 2020). More recently, the use of technology, mostly in the form of applications (apps) on mobile devices (cell phones) have been employed for contract tracing in Australia, China, India and South Korea (Agency France-Press 2020) as well as North Dakota and Utah (Abeler et al. 2020). Contact tracing apps present the possibility of easing resources needed for person-to-person contacting and increasing the speed at which people are contacted (Abeler et al. 2020).

Would it be plausible to use contact tracing apps in existing or new well-being programs and projects to aid in gathering data about conditions, supplies, and other aspects? Some communities utilize dashboards to provide timely information to residents and other stakeholders, so perhaps contact tracing apps could be expanded for tracking overall community well-being. Related type tracking information approaches already exist in some communities, including in the context of indicators to track progress towards goals, for example. It does not seem too much of a stretch to consider utilizing tracking information for public health purposes at the local and regional levels. Informed by social media as well as objective and subjective data, perhaps such a dashboard could provide real time indicators of well-being.

This commentary seeks to explore dimensions around the use of such apps to help manage in times of crisis. Community well-being focuses on the overall state of people living in their communities or regions, thus it is not too far afield to employ contact tracing to aid in gathering data about the state of well-being.

\section{Contract Tracing Apps: A Few Factors Impacting Their Effectiveness}

The effectiveness of contract tracing apps is dependent on a number of factors. Shahtori et al. (2018) found in the case of the Ebola virus that contact tracing was most effective when it commences within the first few days of an infection's appearance in a community, and when those who are infected are hospitalized at the onset of their infection. Many communities worldwide are well past the early stages of the first appearance of COVID-19 (Maxmen 2020; Elliot and Akpan 2020). Hospitalizing all who are infected is likely impossible due to shortages of hospital beds in some communities (Hao 2020) and the frequency of asymptomatic infections which may account a large percent of those who are infected (Oran and Topol 2020). The effectiveness of contract tracing apps increases as more members of a community install them on their mobile phones and can then accurately record distances (Servick 
2020; Abeler et al. 2020). Reports of the Chinese government using data from contract tracing apps to control people's movement (Agency France-Press 2020) and concerns about data privacy and governance (Abeler et al. 2020) may decrease a communities' trust and use of contact tracing apps. Control over one's data (Abeler et al. 2020) as well as the inclusion of communities in the development or adaptation of contact tracing apps (Yingling et al. 2016) could contribute to greater trust and use of them. A basic premise of community well-being is that there must be participation by those who are impacted within communities, and that this inclusion is undergirded by equity, justice, and fairness (Phillips and Wong 2017). Connecting this premise of participation to use of apps in ways that are trustworthy, transparent and fair will be critical. Building trust and assuring users that data will be used appropriately and respect privacy will be essential, as it is with any community-based initiative.

\section{Community Well-Being in the Face of COVID-19}

Community well-being includes a collective and holistic perspective that encompasses economic, governmental, social, ecological, psychological and other factors (Phillips and Pittman 2015). The COVID-19 pandemic is increasingly devastating communities in economic (job loss, supply chain breakdown, business closures, etc.) (Nicola et al. 2020; Berube 2020), social (closure of schools and inadequate means to educate, loss of support systems, health care system disruption, etc.) (Nicola et al. 2020), ecological (overuse and abuse of parks, breakdown of waste and recycle systems, etc.) (Chow 2020; You et al. 2020; EREF and SWRA Staff 2020) and psychological dimensions (anxiety and depression, loneliness, risk of increased suicide rates, etc.) (Rajkumar 2020; Vitelli 2020). In the US, the pandemic is also highlighting corruption in the nation (Mellman and Eisen 2020) and social injustice in communities (Dorn et al. 2020). It has wreaked particularly devastating impacts on the tourism and aviation industries (Nicola et al. 2020), with many employed in these areas now without work and severe declines in those communities that are tourism dependent.

Analysis by Bliss et al. (2020) indicates the pandemic could last for about 10 years at the rate of transmission at the time of the analysis or longer if immunity is temporary and a widely effective vaccine is not found. With COVID-19 just one of several pandemics in the twenty-first century (Ebola, SARS, H1N1 and MERS being others), it would be unwise to assume that it is the last (World Health Organization n.d.). We believe that over time, the negative impacts of COVID-19 and future pandemics on communities are likely to accumulate and accelerate if the same approaches, goals and objectives are used, whether from another pandemic, continuation of COVID-19, or compounding impacts of natural and human-made disasters that occur during a pandemic.

In our view, it is not enough to just manage the spread of COVID-19 or future pandemics. The impact on communities must also be managed, and it should be approached in ways that protect and secure community well-being in the face of a long-term pandemic as well as future pandemics and any natural or human-made disasters that occur during these times. Giovannini et al. (2020) call for "improvement in the measurement and monitoring of human and social capitals" (p. 9) in an effort towards societal resilience in the face of COVID-19. We propose that contact tracing 
apps can be used to contribute to building community well-being by collecting wellbeing data and community member's ideas for managing the spread of COVID-19 and its impacts on community well-being.

\section{Supporting Resilience and Capacity in Communities}

Communities with strong social capital and capacity are better able to respond to disasters (Phillips 2015a). Social community capacity or capital can be termed resiliency, defined as the ability to respond to and recover from difficulties (Phillips 2015a). Social resiliency is a community's ability to respond or recover in multiple dimensions in addition to social capital, including economic development, information and communication, and community competence (Norris et al. 2008). Community resiliency is achieved for the most part when members in a community work together to achieve goals mutually desired in ways that include those impacted by change (Thornley et al. 2015). A central component of building community social capital and resilience is that of participation (Aldrich and Meyer 2014). By joining together, much more can be achieved, and communities can recover, prosper and flourish. Participatory action research (PAR) is a way to involve community members in understanding and changing what is needed in a community. (McTaggart 1996). Emphasizing collective inquiry, PAR is one way to envelop many issues, opportunities and ideas and use them as the basis for community-led action for desired change.

Local economies have suffered greatly from pandemics with historically high job losses and unemployment levels and a fractured social environment in many places. The economic health of a community depends on interactions that include many components and deep engagement with community members which is often largely based on commercial trade by locally-focused businesses (Phillips 2015b). Both local and big businesses are negatively impacted by declines in local community economies due to COVID-19 (McKinsey and Company 2020), including businesses operating in tourism where a unique community's culture or assets render it a tourist destination (Nicola et al. 2020).

The impact on overall community well-being from COVID-19 extends beyond the financial implications of economic decline as social and economic injustice increases, communities gain greater understanding of these injustices from exposure to them on various media platforms, and social unrest ensues, particularly in the United States (Galea and Abdalla 2020; Baldwin 2020; National Association for the Advancement of Colored People [NAACP] 2020). Thus, there is good reason to fear that as COVID-19 progresses, communities that lack resilience will find themselves in dire situations. We posit that resiliency needs to be fostered and built, and by engaging in approaches that enable community well-being and development, communities will find that weathering the severe crisis that COVID-19 or other disasters may bring is more manageable. It is beyond the scope of this commentary to give a comprehensive explanation for how to do this, however, in brief, to strengthen resiliency communities could strive to:

“...reduce risk and resource inequities; engage local people in mitigation; create organizational linkages; boost and protect social supports; and plan for not having a plan, which requires flexibility, decision-making skills, and trusted sources of information that functions in the face of unknowns (Norris et al. 2008, p. 127). 
We believe that communities must strive to increase social capital and community capacity which in turns builds resiliency to respond to and recover from crisis. Connecting to community members is paramount in this quest.

\section{Contact Tracing and Measuring Well-Being}

When communities are engaged in understanding and managing their well-being, they are more likely to thrive (Musikanski et al. 2019a). The common adages you can't manage what you can't measure and you get what you measure are as true for communities as they are for the business and government sectors. Dimensions of community well-being can be measured using subjective (i.e. a survey or questionnaire) and objective indicators (Frey and Luechinger 2007; Phillips and Wong 2017).

In tandem with their original purpose, contact tracing apps could be used by communities and for communities to manage the impacts of COVID-19 on communities. This could be done by gathering subjective data, such as satisfaction with life; experiences of anxiety, loneliness and happiness; sense of belonging to community and personal safety; trust in government; and the ability to meet ends meet financially. Objective data could be utilized as well, such as employment; housing (and homelessness); economic activity and business, nonprofit and governmental service availability, along with community members' input about interventions to secure and safeguard community well-being. This data gathering process could be engineered to protect data privacy (Abeler et al. 2020) and thus inspire trust in the community.

\section{The Role of Artificial Intelligence}

There are few applications of artificial intelligence (AI) for community well-being (Musikanski et al. 2020). AI is being used in the development of contract tracing for COVID-19 with consideration of data privacy by some developers (Sookman 2020). Musikanski et al. (2020) propose that AI be developed to solve social problems and that communities be engaged in the development of AI. It seems plausible that AI could be used as part of a COVID-19 tracing application to protect data privacy by giving people control over the use of their data. Further, these data could help community members and community leaders understand how to use data to safeguard and secure community well-being by influencing decision-making and policy changes. It is entirely feasible that AI will play a much larger role in the future with many aspects of well-being including that of helping build resiliency via information and insight at the community level.

\section{Feasibility of a Contact Tracing and Community Well-Being Safeguarding Framework}

We recommend the exploration of feasibility of development of an app framework for communities to use in partnership with AI developers, creating apps allowing for contact tracing, gathering of community well-being data, and community members' ideas for interventions for securing and safeguarding community well-being. The feasibility study could include multidisciplinary representation of epidemiological 
science, community well-being and development, AI technology, as well as representatives of a community. The feasibility could explore the questions of:

1) How can contact tracing through apps include engagement via community-based processes such as participatory action research (PAR) for ensuring inclusion and fairness as well as human centric AI design practices in the development, implementation and management of the app?

2) What are privacy and other related concerns and what are the mechanisms in place for guiding their management, such as the European Union's General Data Protection Regulation (GDPR) that provide data management standards, and for integrating privacy protections into contact tracing apps?

3) How would unintended consequences be identified, monitored and managed?

The framework could allow community members to measure and monitor their own well-being by entering their data on a periodic basis and receiving scorecards, much like the nonprofit association Happiness Alliance's Happiness Index Scorecard, a tool for measuring personal and community level well-being (available online at www. happycounts.org). For the framework, AI could be developed to provide community members with individually tailored suggestions to secure and safeguard their own wellbeing, much like apps already in use such as Happify, Headspace, MyFitnessPal, MyPositiveSpace and others. The suggestions could be designed to contribute to both individual and collective well-being, within a community-oriented perspective and with an approach similar to PAR. At the same time, the framework could be developed to provide community leaders such as local decision and policy makers in government, business, education and nonprofit sectors understandable and useful presentations of data for the status of the spread of COVID-19 and its impact on community well-being. These presentations could take the form of dashboards or interactive data visualizations and could be tailored to include data from community (i.e. city government, regional agencies, nonprofits, etc.) databases as well as data gathered with the app. They could also be designed to help local decision and policy makers gauge the benefits of interventions suggested by community members. An analogy to the framework is the app Waze whereby people share information (geo-location as well as observations) that allows users of the app to navigate effectively through an area.

This approach is especially suited to tourism destinations which have been devastated by COVID-19 with the loss of over 100 million jobs worldwide (World Travel and Tourism Council [WTTC] 2020). One example is Sapa in northern Vietnam, where over 700 tourism-related businesses closed and over 10,000 jobs were lost (personal communication, Hoang Vuong, ${ }^{1}$ July 14, 2020). Besides helping destinations focus upon the needs of the most vulnerable to expedite COVID-19 recovery, this framework offers potential to facilitate trust and alignment between community members, local governments, the tourism private sector and other industry stakeholders to expedite destination recovery. The approach could:

i. support the implementation of hygiene, health and safety protocols that underpin service-industry recovery,

${ }^{1}$ Director Sapa Tourism Office 
ii. be used as part of destination media strategies,

iii. foster confidence among tourists and potential tourists, and.

iv. enable the redesign of tourism systems to strengthen destination well-being (Musikanski et al. 2019b).

Planet Happiness (ourhertiageourhappiness.org), a project of the Happiness Alliance, has signed partnership agreements with the Pacific Asia Travel Association, the Global Sustainable Tourism Council, the United Nations World Tourism Organization (UNWTO) affiliated World Centre for Excellence in Destinations and is working to promote the development of such a framework. The project aims to engage travel and tourism stakeholders, including tourists, in action-oriented policies, interventions and activities to strengthen community and destination well-being.

\section{Conclusion}

This commentary is provided to encourage thought and consideration of developing an app for connecting contact tracing and community well-being data gathering. By combining elements of community participation with technology and informed governance, we propose that a framework for contact tracing and community well-being safeguarding be developed. Not only would this provide real time data for local governance and to inform residents, it would enable more informed decision-making and policy action. There is much to be gained by doing so although there are difficulties to overcome, not the least of which is to build trust and ensure transparency through data gathering policies at the local governance level. Enough apps exist to learn from, and along with incorporating premises inherent to community well-being such as participation and inclusion, we propose that a framework could provide benefit to help navigate through difficult crisis. Further, having these data, insights, and ideas could help bolster local economic and social situations while mitigating negative impacts created by the current pandemic. A community well-being focused app could bring together community members in ways to foster their own and their community's ability to manage the impacts of COVID-19 by building community social capital and resiliency and as a community survive and thrive. We hope you will join us in efforts to more fully explore a framework for contact tracing and community well-being data gathering.

Acknowledgements Bogdana Rakova, b.rakova@gmail.com

\section{References}

Abeler, J., Bäcker, M., Buermeyer, U., \& Zillessen, H. (2020). COVID-19 contact tracing and data protection can go together. JMIR mHealth and uHealth, 8(4), e19359. https://doi.org/10.2196/19359.

Agency France-Press. (2020). Coronavirus contract tracing; which counties are doing what. Gadgets 360. Retrieved July 25, 2020 from https:/gadgets.ndtv.com/apps/features/coronavirus-contact-tracing-appswhich-countries-are-doing-what-2237952 
Aldrich, D., \& Meyer, M. (2014). Social capital and community resilience. American Behavioral Scientist, 59(2), 253-269. https://doi.org/10.1177/000276421455029.

Baldwin, R. (2020). The COVID-19 upheaval scenario: Inequality and pandemic make an explosive mix. Vox [Online Resource]. Retrieved August 12, 2020 from https://voxeu.org/article/inequality-and-pandemicmake-explosive-mix

Berube, A. (2020). Which city economies did COVID-19 damage first? Brookings. [Online Resource]. Retrieved July 30, 2020 from https://www.brookings.edu/blog/the-avenue/2020/04/29/which-cityeconomies-did-covid-19-damage-first/

Bliss, C., Musikanski, L., Phillips, R. \& Davidson, L. (2020). When will the pandemic end? Suggestions for communities to manage well-being in the face of COVID-19. International Journal for Community Wellbeing (forthcoming). https://doi.org/10.1007/s42413-020-00091.

Centers for Disease Control and Prevention (CDC). (2020). Frequently asked questions. [Online Resource]. Retrieved July 25, 2020 from https:/www.cdc.gov/coronavirus/2019-ncov/faq.html

Chen, D. (2020). You don't need invasive tech for successful contact tracing. Here's how it works. ProPublica. [Online Resource]. Retrieved July 25, 2020 from https://www.propublica.org/article/you-dont-needinvasive-tech-for-successful-contact-tracing-heres-how-it-works

Chow, A. (2020). National parks are getting trashed during COVID-19, endangering surrounding communities. Time. Retrieved July 26, 2020 from https://time.com/5869788/national-parks-covid-19/

Dorn, A., Cooney, E., \& Sabin, M. (2020). COVID-19 exacerbating inequalities in the US. Lancet, 395(10232), 1243-1244. https://doi.org/10.1016/S0140-6736(20)30893-X.

Elliot, K. \& Akpan, N. (2020). How the new coronavirus surges compared to New York CIty's peak. National Geographic. Retrieved July 25, 2020 from https:/www.nationalgeographic.com/science/2020/07/hownew-coronavirus-surges-compare-new-york-city-peak-cvd/?cmpid=org=ngp::mc=crm-email::src=ngp:: cmp=editorial::add=SpecialEdition_20200710\&rid=04AEB8EC70EFD525CAB2B0B73B815C1

EREF \& SWRA Staff. (2020). Weaterhin the essentials: a look inside the COVID-10 impact on the waste and recycling industry. Waste 360. [Online Resource]. Retrieved July 26, 2020 from https://www.waste360. $\mathrm{com} /$ business/weathering-essential-look-inside-covid-19-impact-waste-and-recycling-industry

Frey, B., \& Luechinger, S. (2007). Concepts of happiness and their measurement. Hessen, Germany: Metropolis Verlag.

Galea, S., \& Abdalla, S. (2020). COVID-19 pandemic, unemployment, and civil unrest: Underlying deep racial and socioeconomic divides. JAMA, 324(3), 227-228. https://doi.org/10.1001/jama.2020.11132.

Giovannini, E., Campolongo, F, Cariboni, J., Manca, A. \& Benczúr, P. (2020). Luxembourg: European Union. https://doi.org/10.2760/062495. [Online Resource]> Retrieved August 2, 2020 from: https://ec. europa.eu/jrc/en/publication/eur-scientific-and-technical-research-reports/time-transformative-resiliencecovid-19-emergency

Hao, K. (2020). Here are the states that will have the worst hospital bed shortages. MIT technology review. [Online Resource]. Retrieved July 25, 2020 from https:/www.technologyreview.com/2020/04/07/ 998527/coronavirus-us-states-worst-h

Maxmen, A. (2020). How much is coronavirus spreading under the radar? Nature. https://doi.org/10.1038/ d41586-020-00760-8. [Online Resource].

McKinsey \& Company. (2020). COVID-19: implications for business. [Online Resource]. Retrieved August 12, 2020 from https://www.mckinsey.com/business-functions/risk/our-insights/covid-19-implicationsfor-business\#

McTaggart, R. (1996). Guiding principles for participatory action research. In R. McTaggert (Ed.), Participatory action research: International contexts and consequences (pp. 25-44). Albany: State University of New York Press.

Mellman, A. \& Eisen, N. (2020) Addressing the other COVID crisis: Corruption, Brookings. [Online Resource]. Retrieved July 26, 2020 from https://www.brookings.edu/research/addressing-the-othercovid-crisis-corruption/

Musikanski, L., Phillips, R., \& Crowder, J. (2019a). The happiness policy handbook, how to make happiness and well-being the purpose of your government. Gabriola Island, BC: New Society Publishers.

Musikanski, L., Rogers, P., Smith, S., Koldowski, J., \& Iriarte, L. (2019b). Planet happiness: a proposition to address overtourism and guide responsible tourism, happiness, well-being and sustainability in world heritage sites and beyond. International. Journal of Community Well-being, 2, 359-371. https://doi.org/ 10.1007/s42413-019-00038-6.

Musikanski, L., Rakova, B., Bradbury, J., Phillips, R., \& Manson, M. (2020). Artificial intelligence and community well-being: a proposal for an emerging area of research. International Journal of Community Well-being, 3, 39-55. https://doi.org/10.1007/s42413-019-00054-6. 
National Association for the Advancement of Colored People (NAACP). (2020). Ten equity implications of coronavirus COVID-19 outbreak in the United States. [Online Resource]. Retrieved August 12, 2020 from https://naacp.org/wp-content/uploads/2020/03/Ten-Equity-Considerations-of-the-CoronavirusCOVID-19-Outbreak-in-the-United-States_Version-2.pdf

Nicola, M., Alsafi, Z., Sohrabi, C., Kerwan, A., Al-Jabir, A., Iosifidis, C., Agha, M., \& Agha, R. (2020). The socio-economic implications of the coronavirus pandemic (COVID-19): a review. International Journal of Surgery, 78, 185-193. https://doi.org/10.1016/j.ijsu.2020.04.018.

Norris, F. H., Stevens, S. P., Pfefferbaum, B., Wyche, K. F., \& Pferfferbaum, R. L. (2008). Community resilience as a metaphor, theory, set of capacities, and strategy for disaster readiness. American Journal of Community Psychology, 41(1), 127-150. https://doi.org/10.1007/s10464-007-9156-6.

Oran, D., \& Topol, E. (2020). Prevalence of asymptomatic SARS-CoV-2 infection. Annals of Internal Medicine., 173, 362-367. https://doi.org/10.7326/M20-3012.

Phillips, R. (2015a). Community quality-of-life indicators to avoid tragedies. In R. Anderson (Ed.), World suffering and quality of life (pp. 293-304). Dordrecht: Springer.

Phillips, R. (2015b). Building community well-being across sectors with "for benefit" community business. In S. J. Lee, Y. Kim, \& R. Phillips (Eds.), Community well-being and community development, conceptions and applications (pp. 25-37). Dordrecht: Springer.

Phillips, R., \& Pittman, R. (Eds.). (2015). Introduction to community development. London: Routledge/Taylor \& Francis Group.

Phillips, R., \& Wong, C. (2017). Handbook of community well-being research. Dordrecht: Springer.

Rajkumar, R. (2020). COVID-19 and mental health: a review of the existing literature. Asian Journal of Psychiatry, 52 (102066). https://doi.org/10.1016/j.ajp.2020.102066.

Servick, K. (2020). COVID-19 contact tracing apps are coming to a phone near you. How will we know whether they work? Science Mag. Retrieved July 22, 2020 from https://www.sciencemag.org/news/2020/ 05/countries-around-world-are-rolling-out-contact-tracing-apps-contain-coronavirus-how

Shahtori, N., Scoglio, T., \& Shaneh, F. (2018). Quantifying the impact of early state contact tracing on controlling ebola diffusion. Mathematical Biosciences and Engineering, 15(5), 116-1180. https://doi.org/ 10.3934/mbe.2018053.

Sookman, B. (2020). AI and contract tracing: How to protect privacy while fighting the COVID-19 pandemic. Macdonald-Laurier Institute. [Online Resource]. Retrieved July 26, 2020 from https://macdonaldlaurier. ca/files/pdf/20200416_COVID-Privacy_Sookman_COMMENTARY_FWeb.pdf

Thornley, L., Ball, J., Signal, L., Aho, K., \& Rawson, E. (2015). Building community resilience: Learning from the Canterbury earthquakes, Kōtuitui. New Zealand Journal of Social Sciences Online, 10(1), 2335. https://doi.org/10.1080/1177083X.2014.934846.

Vitelli, R. (2020). Are we facing a post-COVID-19 suicide epidemic? Psychology today. Retrieved July 22, 2020 from https:/www.psychologytoday.com/us/blog/media-spotlight/202006/are-we-facing-post-covid19-suicide-epidemic

World Health Organization. (n.d.). How the 4 biggest outbreaks since the start this century shattered some long-standing myths. [Online Research]. Retrieved July 26, 2020 from https://www.who.int/csr/disease/ ebola/ebola-6-months/myths/en/

World Health Organization (WHO). (2017). Contract tracing. [Online Resource]. Retrieved July 25 from https://www.who.int/news-room/q-a-detail/contact-tracing

World Travel and Tourism Council (WTTC). (2020). More than 197m travel \& tourism jobs will be lost due to prolonged travel restrictions, according to new research from WTTC. [Online Resource]. Retrieved August 2, 2020 from https://wttc.org/News-Article/More-than-197m-Travel-Tourism-jobs-will-be-lostdue-to-prolonged-travel-restrictions

Yingling, L., Brooks, A., Wallen, G., Peters-Lawrence, M., McClurkin, M., \& Powell-Wiley, T. (2016). Community engagement to optimize the use of web-based and wearable technology in a cardiovascular health and needs assessment study: a mixed methods approach. JMIR Mhealth Uhealth, 4(2), e38. https:// doi.org/10.2196/mhealth.4489.

You, S., Sonne, C., \& Ok, Y. (2020). COVID-19's unsustainable waste management. Science, 386(6498), 1438-141438. https://doi.org/10.1126/science.abc7778.

Publisher's Note Springer Nature remains neutral with regard to jurisdictional claims in published maps and institutional affiliations. 